\title{
Processing of clear and turbid grape juice by a continuous flow UV system
}

\author{
Zehra Kaya, Sevcan Unluturk * \\ Department of Food Engineering, Izmir Institute of Technology, Urla, Izmir, 35437, Turkey
}

\section{A R T I C L E I N F O}

Article history:

Received 2 July 2015

Received in revised form 7 December 2015

Accepted 8 December 2015

Available online 21 December 2015

\section{Keywords:}

Non-thermal process

UV-C irradiation

Fruit juices

Microbial inactivation

Spoilage microorganism

S. cerevisiae

\begin{abstract}
A B S T R A C T
The inactivation of inoculated (S. cerevisiae) and spoilage microorganisms, i.e. yeasts and lactic acid bacteria (LAB), in clear and turbid grape juice was investigated using a pilot scale UV system. The biodosimetry method was used for UV dose prediction in a continuous flow UV reactor. Weibull model was applied for fitting the inactivation data. The flow rates $(774,820 \mathrm{ml} / \mathrm{min})$ in this system were very close to the ones used in fruit juice processing. S. cerevisiae in clear juice was reduced by $3.39 \pm 0.04$ at $65.50 \mathrm{~mJ} / \mathrm{cm}^{2}$ of UV dose. $1.54 \pm$ 0.04 and $1.64 \pm 0.03 \log \mathrm{CFU} / \mathrm{ml}$ reductions were obtained for spoilage yeasts and LAB in turbid juice at UV dose of 78.56 and $67.97 \mathrm{~mJ} / \mathrm{cm}^{2}$, respectively. The soluble solids ( ${ }^{\circ} \mathrm{Brix}$ ) and $\mathrm{pH}$ of grape juice samples were not affected by UV-C treatment $(p>0.05)$. Although the color parameters slightly were changed after irradiation, the color of PCGJ and FSTGJ did not show visual difference compared to the untreated samples. Industrial relevance: UV light has a potential to reduce the levels of microbial contamination in liquid foods. Although grape juice has many beneficial health effects, it has a fairly short shelf life. Therefore, pasteurization is required. But the thermal pasteurization has some undesired effects on the juice quality. Consumer demands for high quality fruit juice with fresh-like characteristics have markedly expanded in recent years. In the current study, the microbial inactivation efficiency of a pilot scale UV system for non-thermal treatment of clear and turbid grape juice was evaluated under conservative conditions. Most of the physicochemical properties of grape juice samples were not significantly affected from UV-C treatment $(p>0.05)$. This would be a major advantage in the processing of nutritious juice products.
\end{abstract}

(C) 2015 Elsevier Ltd. All rights reserved.

\section{Introduction}

Spoilage microorganisms such as yeasts, moulds and acid-tolerant bacteria that can grow naturally in fruit juices may lead to off-flavors and off-odors reducing the quality of the juices (Tournas, Heeres, \& Burgess, 2006). On the other hand, the spoilage and contamination of fruit juice by pathogenic microorganisms are the major concerns. The growth of those microorganisms must be avoided in the juice by applying several prevention methods.

Although the thermal processing provides an effective pasteurization, long and stable shelf life for the juices, several sensorial and nutritional quality problems can occur such as permanent loss of flavor and taste, degradation of nutrients and development of undesirable browning reactions emerged from heating (Garde-Cerdan, Arias-Gil, Marselles-Fontanet, Ancin-Azpilicueta, \& Martin-Belloso, 2007). In order to prevent harmful effects of the heat, non-thermal processes are investigated as an alternative preservation method for more freshlike fruit juices (Noci et al., 2008).

\footnotetext{
* Corresponding author at: Department of Food Engineering, Engineering Faculty, Izmir Institute of Technology, Urla, Izmir, 35430, Turkey. Tel.: + 90232 7506296; fax: + 90232 7506196.

E-mail address: sevcanunluturk@iyte.edu.tr (S. Unluturk).
}

UV-C irradiation can be an alternative cost effective non-thermal process for heat sensitive products such as liquid egg products, fruit juices and beverages (Donahue, Canitez, \& Bushway, 2004; Unluturk, Atilgan, Baysal, \& Tarı, 2008; Gayan, Monfort, Alvarez, \& Condon, 2011). UV-C light between 200 and $280 \mathrm{~nm}$ in the electromagnetic spectrum has a lethal impact on microorganisms such as bacteria, yeasts, moulds and viruses (Bintsis, Litopoulou-Tzanetaki, \& Robinson, 2000). The most efficient germicidal UV light is emitted at $254 \mathrm{~nm}$ (Koutchma, Forney, \& Moraru, 2009). There are numerous studies about evaluating the efficacy of UV light for the inactivation of spoilage and pathogenic microorganisms in liquid foods (Ngadi, Smith, \& Cayouette, 2003; Tran \& Farid, 2004; Koutchma \& Parisi, 2004; Koutchma, Parisi, \& Unluturk, 2006; Noci et al., 2008; Unluturk et al., 2008; Gabriel \& Nakano, 2009; Unluturk, Atilgan, Baysal, \& Unluturk, 2010).

UV-C light has been used in the water treatment for many years (Guerrero-Beltran \& Barbosa-Canovas, 2004). Small, medium and large volume of water can be disinfected efficiently by using different types of commercial UV units available in the market based on different transmittance properties. But the stringent optical properties of liquid foods do not allow using most of these commercial units in the processing of these foods. The efficiency of UV-C treatment is highly affected by the reduced penetration depth as a result of the presence of solutes and 
particles (Wright, Sumner, Hackney, Pierson, \& Zoecklein, 2000). Different types of UV reactors have been designed to overcome this limitation. The first design approach used a thin-film flow for liquid foods, e.g. CiderSure reactor that was developed as a UV light processing equipment in 1998 (FPE Inc., Macedon, NY) (CiderSure, 2010) and the Taylor-Couette flow UV reactor constructed by Forney and Pierson in 2003 (Forney \& Pierson, 2003). A second design approach focused on increasing of the turbulence within a UV reactor, e.g. Aquionics UV reactor (Hanovia Ltd., Slough, England), SurePure (SurePure Inc., Milnerton, South Africa) and Dean Flow UV reactors such as Salcor UV module (Salcor Inc., CA) and UVivatec System (Bayer Technology Services GmbH, Leverkusen, Germany) (Koutchma, 2008; Müller et al., 2013). Only, CiderSure (FPE Inc., Rochester, NY) and SurePure (SurePure Inc., Milnerton, South Africa) offer some commercial UV systems suitable for small, midsize and large operations of liquid food products (Koutchma, 2008; CiderSure, 2010). On the other hand, some UV systems that are mostly appropriate for the water disinfection can also be used for low transmittance liquids. These systems can be more economical and feasible for small juice production.

The objective of this study was to assess the effectiveness of UV-C irradiation in non-thermal treatment of clear and turbid grape juice using a pilot scale continuous flow UV system, i.e. a typical of those used for water sterilization, under conservative processing conditions. For this purpose freshly squeezed turbid white grape juice (FSTGJ) and pasteurized clear white grape juice (PCGJ) were selected to represent turbid and clear liquid foods. The flow rates (774 and $820 \mathrm{ml} / \mathrm{min}$ ) used with this system were very close to the ones used in fruit juice processing. Applied UV doses for each product processed in a continuous UV system were determined by a biodosimetry method. The effect of UV-C irradiation on the physicochemical properties of grape juice samples before and after treatment was also evaluated.

\section{Materials and methods}

\subsection{Grape juice}

Commercial PCGJ made from seedless grapes (Sultana variety of Vitis vinifera $L$.) (Kavaklıdere, Ankara) was purchased from a local market in Izmir, Turkey. Commercial PCGJ contains citric acid and no other preservatives. Background flora of pasteurized samples was checked by surface plating on Tryptic Soy Agar (TSA, Merck, Darmstadt, Germany) for enumeration of total aerobic bacteria and Violet Red Bile Agar (VRBA, Merck, Darmstadt, Germany) to determine the number of coliforms prior to UV treatment.

White grapes (seedless sultana) were purchased from a market place in Izmir, Turkey. They were washed with tap water and pressed by a household table top fruit juice extractor (Arcelik, Robolio, Istanbul, Turkey). The juice was then filtered through a two layer cheese cloth. In order to protect the color of juice, L-ascorbic acid (400 mg/l) (Merck, Germany) was added in the allowable range of Codex Alimentarious Commission (FAO, Food and Agriculture Organization of the United Nations, 1981). FSTGJ samples were packed in plastic bottles and stored in the freezer $\left(-18^{\circ} \mathrm{C}\right)$ until used.

\subsection{Physicochemical properties of grape juice samples}

Absorbance of the samples was measured by a UV-Visible Spectrophotometer (Carry 100 Bio, Varian Inc., CA, USA). Absorption coefficient $\left(A_{\mathrm{e}}\right)$ was calculated according to Unluturk et al. (2008). Turbidity of the samples was measured by a turbidimeter (Model 2100AN IS, HACH Co., USA). Results were expressed as Nephelometric Turbidity Unit (NTU).

CIE color parameters $\left(L^{*}, a^{*}, b^{*}\right)$ were determined by a Chromometer (Minolta CR 400, Konica Inc., Japan). Total color difference $(\Delta E)$ and browning index (BI) (Palou, Lopez-Malo, Barbosa-Canovas, Welti-
Chanes, \& Swanson, 1999) of the samples were calculated from Eqs. (1) and (2), respectively:

$$
\begin{aligned}
& \Delta \mathrm{E}=\sqrt{\left(\Delta L^{*}\right)^{2}+\left(\Delta a^{*}\right)^{2}+\left(\Delta b^{*}\right)^{2}} \\
& B I=100 * \frac{\frac{\left(a^{*}+1.75 L^{*}\right)}{\left(5.645 L^{*}+a^{*}-3.012 b^{*}\right)}-0.31}{0.172}
\end{aligned}
$$

The reference value for $\Delta E$ was the untreated juice. Soluble solids ( ${ }^{\circ} \mathrm{Brix}$ ) and $\mathrm{pH}$ were measured at $20^{\circ} \mathrm{C}$ by a refractometer (MettlerToledo RE40D, AEA Investors Inc., USA) and a pH meter (HANNA Instruments, USA), respectively. A densitometer (Kyoto Electronics DA, Japan) was used to measure the density of samples. Viscosity measurements were conducted by using concentric cylinder viscometer (Brookfield DV II + Pro, Brookfield Engineering Lab. Inc., MA, USA) equipped with a cylindrical spindle (LV-1) (cylinder diameter $18.84 \mathrm{~mm}$, length $115 \mathrm{~mm}$, beaker diameter $86.30 \mathrm{~mm}$ and $600 \mathrm{ml}$ of sample volume).

Titratable acidity of the white grape juice samples was measured by titrating juice samples with a standardized $0.1 \mathrm{~N}$ sodium hydroxide $(\mathrm{NaOH})$ solution and the results were expressed as grams of tartaric acid per $100 \mathrm{ml}$ of fruit juice (Eq. (3)):

$T A(\%)=(V) *(f) *(E) * 100 / M$

where $V$ is the volume of $0.1 \mathrm{~N} \mathrm{NaOH}(\mathrm{ml}), f$ is the normality factor of $\mathrm{NaOH}, E$ and $M$ are the milliequivalent weight of tartaric acid and volume of the sample, respectively.

Particle size distribution of FSTGJ was determined by a particle size analyzer (Mastersizer 2000, Malvern Instruments Ltd., Malvern, UK) that utilizes the phenomenon of scattered light from laser beams projected through a stream of particles. The grape juice particle size distribution was measured based on the volume percentage. Particle size was explicated in terms of diameter at maximum peak of the graph (Dpeak) and the volume-weighted mean diameter $(D[4,3])$ was calculated from Eq. (4) where $n_{i}$ was a symbolized number of particles of diameter $\left(d_{i}\right)$ (Betoret, Betoret, Carbonell, \& Fito, 2009).

$(D[4,3])=\sum_{i} n_{i} d_{i}^{3} / \sum_{i} n_{i} d_{i}^{4}$

Microbiological quality and some of the physical properties of the samples were summarized in Table 1.

\subsection{Biodosimetry method}

It is challenging to measure the dose distribution delivered by a continuous flow UV reactor. Computing methods, actinometry and biodosimetry are different approaches that can be used for evaluating the dose of UV processing systems. Among them biodosimetry is commonly used (Koutchma et al., 2009). In this method, UV dose-response

Table 1

Microbiological quality and some of the physical properties of untreated PCGJ and FSTGJ.

\begin{tabular}{lll}
\hline Property & PCGJ & FSTGJ \\
\hline Total aerobic count $(\log$ CFU/ml) & ND & $5.38 \pm 0.01$ \\
Total coliform $(\log$ CFU/ml) & ND & ND \\
Density (g/cm ${ }^{3}$ ) & $1.068 \pm 0.002$ & $1.065 \pm 0.00$ \\
Viscosity (cP) & 2.10 & 5.30 \\
pH & $3.45 \pm 0.01$ & $4.40 \pm 0.01$ \\
Titratable acidity (\%) & $0.37 \pm 0.00$ & $0.17 \pm 0.03$ \\
Turbidity (NTU) & $32.5 \pm 0.14$ & $105 \pm 2.12$ \\
Brix (\%) & $17.42 \pm 0.01$ & $16.38 \pm 0.00$ \\
Absorbance coefficient (at $254 \mathrm{~nm})$ & $5.63 \pm 0.01$ & $13.26 \pm 0.02$ \\
\hline
\end{tabular}

Results were presented as mean \pm standard error $(n=3)$. ND: not detectable. 
curve of a microorganism is constructed using a bench top collimated beam UV apparatus. Then, UV dosage delivered in a continuous flow UV system is estimated based on this curve. This estimated dose value is called as "reduction equivalent dose" (RED). The details of RED can be found elsewhere (Koutchma et al., 2009).

\subsubsection{Target microorganisms and growth conditions}

Spoilage microorganisms (mostly yeasts and LAB) and Saccharomyces cerevisiae (NRRL Y-139) were used as target microorganisms for FSTGJ and PCGJ, respectively.

In our previous studies, $3 \mathrm{~min} \mathrm{UV}-\mathrm{C}$ treatment at $45.36 \mathrm{~mJ} / \mathrm{cm}^{2}$ and $77.2 \mathrm{~mJ} / \mathrm{cm}^{2}$ was resulted in $3.33 \pm 0.20$ and $5.75 \pm 0.25 \mathrm{log} \mathrm{CFU} / \mathrm{ml}$ reductions of $S$. cerevisiae and $E$. coli K12, a non-pathogenic surrogate of E. coli 0157:H7, in clear grape juice (Hakguder, 2009; Kaya, 2011). It has been known that yeast, bacterial spores, molds, and viruses are more resistant to UV light than Gram-negative bacteria and Gram-positive bacteria (Lopez-Malo \& Palau, 2005). In this study, S. cerevisiae (NRRL Y-139) and spoilage microorganisms (yeast and molds, lactic acid bacteria) were selected as target microorganisms to provide conservative estimate for evaluation of the UV-C irradiation effect on clear and turbid white grape juice.

The filtered FSTGJ was naturally fermented (spoiled) by stirring at $100 \mathrm{rpm}$ and $30^{\circ} \mathrm{C}$ in the orbital shaker (Thermo Electron Corp., Ohio, USA) for $24 \mathrm{~h}$. After fermentation, a gram-staining was carried out and showed that spoilage microorganisms in the FSTGJ were mainly composed of yeasts and lactic acid bacteria (LAB). Total yeasts and molds (YM) were counted on Potato Dextrose Agar (PDA, Difco Laboratories, Detroit, MI) acidified to pH 3.5 with 10\% tartaric acid (Merck, Darmstadt, Germany) at $25{ }^{\circ} \mathrm{C}$ for $2-5$ days using spread-plate technique. LAB was counted on De Man Rogosa and Sharp Agar (MRS, Merck, Darmstadt, Germany) using pourplate method after incubation at $30{ }^{\circ} \mathrm{C}$ for 2 days. Final microbial load of the FSTGJ was adjusted to ca. $6 \log \mathrm{CFU} / \mathrm{ml}$ yeasts and ca. $8 \log \mathrm{CFU} / \mathrm{ml}$ LAB by diluting with freshly squeezed white grape juice before the UV treatments.

Cultivation of $S$. cerevisiae was carried out by using peptone-yeast extract-malt extract (PYM) broth acidified to $\mathrm{pH}$ 4.5. The microorganisms were incubated by shaking $225 \mathrm{rpm}$ in an orbital shaker (Thermo Electron Corp., Ohio, USA) at $30{ }^{\circ} \mathrm{C}$ overnight. S. cerevisiae cells were centrifuged at $3010 \mathrm{rpm}$ for $15 \mathrm{~min}$ at $4{ }^{\circ} \mathrm{C}$ with a centrifuge (Rotina 380R, Hettich Centrifuge, UK) and washed with $0.85 \%$ sodium chloride $(\mathrm{NaCl})$ solution twice. The supernatant was removed and cells were inoculated into PCGJ at a concentration of ca. $6 \log \mathrm{CFU} / \mathrm{ml}$ before being exposed to UV-C treatment. The enumeration was carried out on PDA as described above.

\subsubsection{Bench top collimated beam UV apparatus}

Inoculated samples were exposed to UV-C irradiation using a collimated beam apparatus described in Unluturk et al. (2010). The UV lamp at $254 \mathrm{~nm}$ wavelength (UVP XX-15, UVP Inc., CA, USA) was switched on for about 30 min prior to UV treatment samples to reduce fluctuations in UV light. The UV intensity at the surface of the
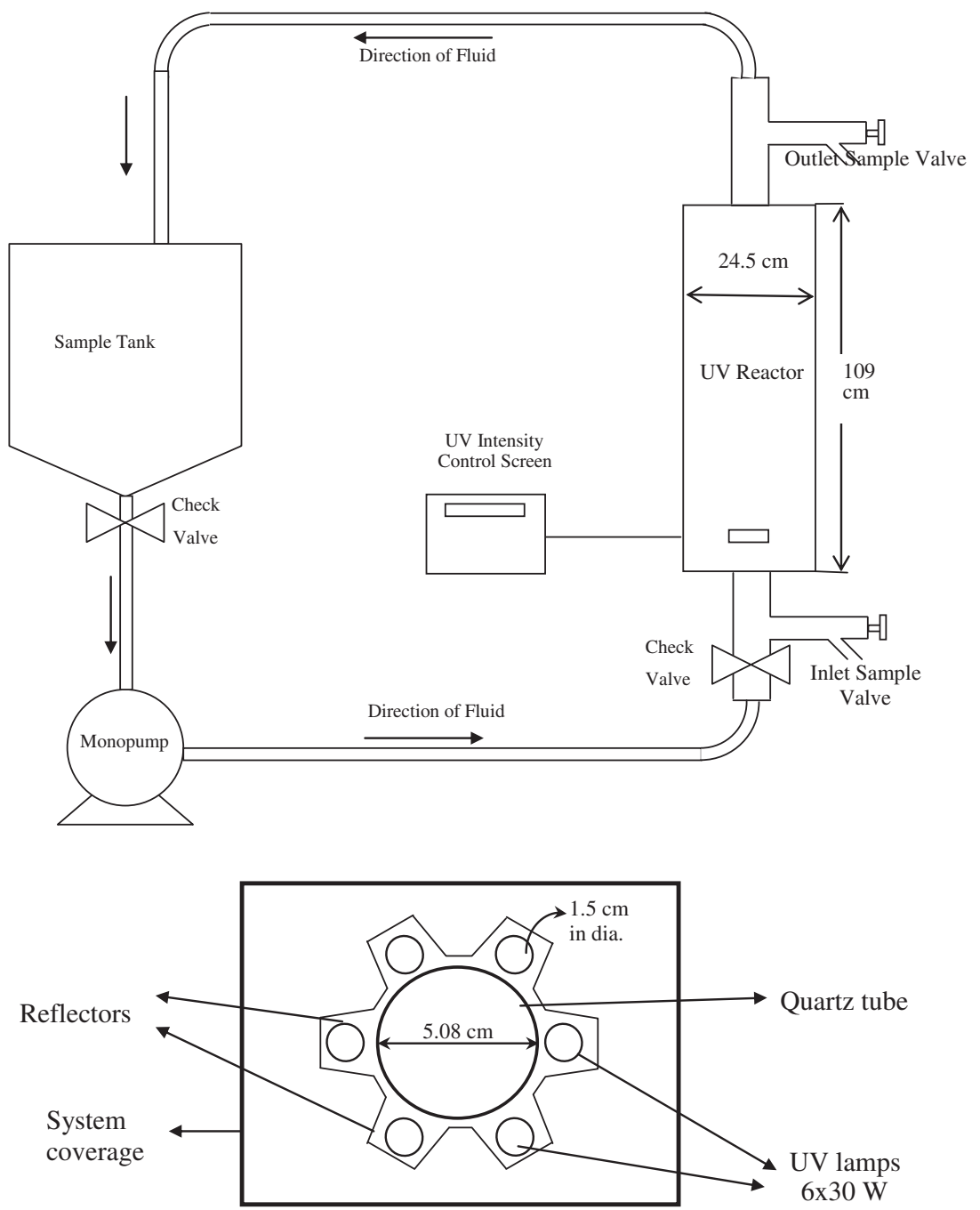

Fig. 1. Pilot scale continuous flow UV system, reactor dimensions and lamp design. 
Table 2

Operational parameters of continuous flow UV system.

\begin{tabular}{lll}
\hline & PCGJ & FSTGJ \\
Property & & \\
\hline Reactor volume (L) & 4.50 & 4.50 \\
Tube diameter (cm) & 5.08 & 5.08 \\
Pump flow rate (ml/min) & 820 & 774 \\
UV exposure time (s) per cycle & 182 & 180 \\
Number of cycles & 8 & 8 \\
Total processing time (min) & 24.27 & 24.00 \\
Re number & 184.36 & 163.87 \\
Velocity $(\mathrm{m} / \mathrm{s})$ & $6.75 \times 10^{-3}$ & $6.37 \times 10^{-3}$ \\
\hline
\end{tabular}

sample (incident intensity (Io) or irradiance) was measured using a radiometer with UVX-25 sensor (UVX, UVP Inc., CA, USA) and average UV intensity in the liquid product was calculated from Beer-Lambert Law (with using simplified radiation model). The UV dose was estimated from the average UV intensity and exposure time (Unluturk et al., 2008).

The grape juice samples were subjected to UV dosages ranging from 0 to $282.24 \mathrm{~mJ} / \mathrm{cm}^{2}$. The log reductions of microorganisms inoculated in different liquid medium were plotted against UV doses to construct the UV dose-response curve.

\subsubsection{Modeling of UV-C inactivation kinetics}

The microbial reduction data was analyzed using a Weibull model described in Unluturk et al. (2010). Weibull distribution function is composed of two parameters ( $\alpha$ and $\beta$ ) given in the following correlation (Van Boekel, 2002):

$\log _{10}\left(\frac{N}{N_{0}}\right)=-\frac{1}{2.303}\left(\frac{t}{\alpha}\right)^{\beta}$

In the case of $\beta=1$, the inactivation curve appears first order linearly oriented. Upward concavity (tailing) of the inactivation curve $(\beta<1)$ indicates stress adaptation of target microorganism, survived after UV exposure. Downward concavity (shoulder) $(\beta>1)$ shows accumulated damaging rates of UV in the cells. The reliable time $\left(t_{R}\right)$ is estimated from these parameters. $t_{R}$ is the reliable life time indicating $90 \%$ reduction of the number of microorganism (Van Boekel, 2002). It is similar to the $D$ value (the time necessary to reduce the number of microorganisms by a factor of 10) but it shows high dependency on $\beta$. $t_{\mathrm{R}}$ for UV inactivation is calculated using Eq. (6) (Van Boekel, 2002):

$t_{R}=\alpha(2.303)^{\frac{1}{\beta}}$

\subsection{Pilot scale continuous flow UV system and inactivation treatments}

Continuous flow UV system (Fig. 1) used in this study was primarily composed of a vertical UV reactor (E10, Wedeco-Durco AG Water Technology, Germany) equipped with 6 low-pressure mercury UV lamps (total power $30 \mathrm{~W}$, light emission at $254 \mathrm{~nm}$ ) positioned around a protective quartz tube (diameter, i.e. UV path length, $5.08 \mathrm{~cm}$ ). The liquid is pumped at $25{ }^{\circ} \mathrm{C}$ with a stainless steel mono-pump (Inokstek Inc., Turkey) equipped with a frequency invertor. Maximum operational capacity of the UV system is $333 \mathrm{l} / \mathrm{min}$ for clear liquids and $83 \mathrm{l} / \mathrm{min}$ for low transmittance liquids (Wedeco [Operating Manual], 2007). The temperatures of juice samples before and after UV processing were measured by using K-type thermocouple (CEMDT-8891E, Shenzhen, China) manually installed at the entrance and exit of the UV reactor. The maximum temperature rise was recorded as $7-8{ }^{\circ} \mathrm{C}$. The heat effect was ignored in the UV reactor.

The operational parameters are summarized in Table 2. Grape juice samples exhibited a Newtonian behavior (Kaya, 2011). Reynolds numbers of Newtonian fluids were estimated by Eq. (7) (Telis-Romero, Thomas, Bernardi, Telis, \& Gabas, 2006):

$\operatorname{Re}=\frac{D v \rho}{\eta} \quad($ Newtonian $)$

where Re, $D, v, \rho$, and $\eta$ refer to Reynolds number, diameter (m), average flow velocity $(\mathrm{m} / \mathrm{s})$, density $\left(\mathrm{kg} / \mathrm{m}^{3}\right)$ and viscosity (Pa $\mathrm{s}$ ), respectively.

PCGJ and FSTGJ were pumped and re-circulated through the UV system at flow rates of $820 \mathrm{ml} / \mathrm{min}$ and $774 \mathrm{ml} / \mathrm{min}$, respectively. Sampling was done after each cycle. Enumerations of total aerobic, total yeast and mold (YM), S. cerevisiae, and LAB counts were carried out according to methods given in Section 2.3.1. Survival curves were generated for grape juice samples.

\subsection{Statistical analysis}

All experiments were replicated three times. Weibull model was applied for the evaluation of UV inactivation data by using MATLAB ${ }^{\circledR}$ (MATLAB $® 6$, Mathworks Inc., Natic, MA, USA). In order to determine the suitability of fitted function on the inactivation data, the root mean squared error (RMSE) was computed using the calculated and experimentally determined logarithmic reductions as described in Unluturk et al. (2010). Two-sample t-test (Microsoft Excel, Redmond, WA, USA) was applied to determine significant differences between the means of physicochemical properties measured before and after UV irradiation at a 95\% confidence level.

\section{Results and discussion}

\subsection{Effects of UV-C irradiation on physicochemical properties of PCGJ and} FSTGJ

The effects of UV-C irradiation on the physicochemical properties of PCGJ and FSTGJ were shown in Table 3 . The soluble solids ( ${ }^{\circ} \mathrm{Brix}$ ) and $\mathrm{pH}$ of grape juice samples were not affected by UV-C treatment. Many

Table 3

The effect of UV-C irradiation on the physicochemical properties of PCGJ and FSTGJ.

\begin{tabular}{|c|c|c|c|c|c|}
\hline \multirow{2}{*}{\multicolumn{2}{|c|}{ Parameter }} & \multicolumn{2}{|l|}{ PCGJ } & \multicolumn{2}{|l|}{ FSTGJ } \\
\hline & & Untreated & $\begin{array}{l}\text { UV-C } \\
\text { irradiated }\end{array}$ & Untreated & $\begin{array}{l}\text { UV-C } \\
\text { irradiated }\end{array}$ \\
\hline \multicolumn{2}{|l|}{$\mathrm{pH}$} & $3.45 \pm 0.01$ & $3.46 \pm 0.01$ & $4.41 \pm 0.01$ & $4.42 \pm 0.01$ \\
\hline \multicolumn{2}{|c|}{ Titratable acidity (\%) } & $0.37 \pm 0.00$ & $0.36 \pm 0.00$ & $0.17 \pm 0.03$ & $0.13 \pm 0.01^{*}$ \\
\hline \multicolumn{2}{|c|}{ Turbidity (NTU) } & $32.50 \pm 0.14$ & $7.70 \pm 0.03^{*}$ & $105.50 \pm 2.12$ & $107.50 \pm 0.70$ \\
\hline \multicolumn{2}{|c|}{$\operatorname{Brix}(\%)$} & $17.42 \pm 0.01$ & $17.88 \pm 0.01$ & $16.38 \pm 0.00$ & $16.45 \pm 0.02$ \\
\hline \multicolumn{2}{|c|}{ Absorption coefficient } & $5.63 \pm 0.01$ & $4.85 \pm 0.01^{*}$ & $13.26 \pm 0.02$ & $7.63 \pm 0.01^{*}$ \\
\hline \multirow[t]{5}{*}{ Color } & $(\Delta \mathrm{E})$ & - & $0.94 \pm 0.18$ & - & $1.73 \pm 0.35$ \\
\hline & (BI) & $57.65 \pm 0.05$ & $57.51 \pm 0.00$ & $58.36 \pm 0.02$ & $58.63 \pm 0.01^{*}$ \\
\hline & $L^{*}$ & $51.45 \pm 0.02$ & $52.36 \pm 0.17^{*}$ & $53.30 \pm 0.21$ & $51.60 \pm 0.15^{*}$ \\
\hline & $a^{*}$ & $1.30 \pm 0.01$ & $1.10 \pm 0.01^{*}$ & $-0.03 \pm 0.03$ & $0.23 \pm 0.01^{*}$ \\
\hline & $b^{*}$ & $2.05 \pm 0.09$ & $2.01 \pm 0.01$ & $4.28 \pm 0.02$ & $4.39 \pm 0.01^{*}$ \\
\hline
\end{tabular}

* Significantly different between untreated and treated juice samples $(p<0.05)$. 
studies were reported that UV-C light did not have an effect on $\mathrm{pH}$, brix and titratable acidity of fruit juices which were consistent with the results of this study (Noci et al., 2008; Torkamani \& Niakousari, 2011; Ochoa-Velasco \& Guerrero-Beltran, 2013). Only, the titratable acidity of FSTGJ was significantly reduced after UV-C treatment $(p<0.05)$. This was due to degradation of L-ascorbic acid that was originally added to fresh juice as an antioxidant agent. The ascorbic acid was found to be diminished after UV-C treatment. Rameshkumar, Sivasudha, Jeyadevi, Arul Ananth, and Pradeepha (2012) had similar results. They found that L-ascorbic acid content of the fresh grape juice was decreased from $6.46 \pm 0.04$ to $1.20 \pm 0.02 \mu \mathrm{g} / \mathrm{ml}$ after 30 min UV-C light treatment.

FSTGJ had high amount of suspended solids resulted in higher turbidity (105 $\pm 2.12 \mathrm{NTU})$ and absorption coefficient $(13.26 \pm$ $\left.0.02 \mathrm{~cm}^{-1}\right)$ compared to PCGJ $\left(32.5 \pm 0.14\right.$ NTU, $\left.5.63 \pm 0.01 \mathrm{~cm}^{-1}\right)$ (Table 3). No particles were detected in PCGJ. On the other hand, FSTGJ resulted in a suspension of particles ranging from 0.63 to $316 \mu \mathrm{m}$ in size. Fig. 2 shows the FSTGJ particle size distribution based on volume percentage. Particle sizes of FSTGJ were distributed in different ranges. The main distribution was in the range of 0.63 and $69.18 \mu \mathrm{m}$ with an average particle diameter ([D4,3]) of $32.55 \mu \mathrm{m}$. The maximum peak of the distribution was $5.83 \mu \mathrm{m}$ (Dpeak). It was indicated that the most existing particles in the total volume of FSTGJ had a diameter of $5.83 \mu \mathrm{m}$. Similarly, Unluturk, Arastoopour, and Koutchma (2004) demonstrated that apple cider was composed of particles having a bimodal particle size distribution. Particles of apple cider are distributed in two ranges, 1-26 $\mu \mathrm{m}$ with an average diameter of $7.6 \mu \mathrm{m}$, and 30$592 \mu \mathrm{m}$ with an average diameter of $225 \mu \mathrm{m}$. The suspended materials (particles) in juice cause shadowing effect resulting in low UV light penetration allowing microorganisms to survive during UV-C irradiation and reduce the efficiency of UV reactor. It also contributes to turbidity and absorption coefficient. While the turbidity was not affected, the absorption coefficient of FSTGJ was declined after UV treatment. The major cause of this might be due to degradation of color pigments and ascorbic acid that was originally added to fresh juice by UV-C treatment (Koutchma et al., 2009). The turbidity and absorption coefficient of PCGJ were significantly reduced after UV exposure $(p<0.05)$ (Table 3 ). Donahue et al. (2004) also indicated a decrease in turbidity of the apple cider exposed to UV-C irradiation. The decrease in turbidity and absorption coefficient of PCGJ might be attributed to change in color pigments during UV-C exposure.

The color parameters $\left(L^{*}, a^{*}, b^{*}, \Delta E, B I\right)$ of FSTGJ were highly affected by UV-C irradiation compared to PCGJ (Table 3). Falguera, Pagan, and Ibarz (2011) observed that UV irradiation is resulted in lighter color in apple juice (higher $L^{*}$ value) due to loss of some of the color pigments. Comparable results were found for PCGJ in this study. $L^{*}$ value of PCGJ was increased from $51.45 \pm 0.023$ to $52.36 \pm 0.17$. On the other hand, the decrease of $L^{*}$ and increase of $a^{*}$ of FSTGJ treated with UV-C irradiation were explained by the presence of enzymatic activity causing a change in the color of the fresh juice. Koutchma et al. (2009) reported that PPO enzyme causing browning cannot be inactivated by UV light.
The decrease of $L^{*}$ (darker) and increase of $a^{*}$ value (reddish) in fresh juice were reported as a good indicator of browning (Gomez, Alzamora, Castro, \& Salvatori, 2010). Additionally, the increase of $a^{*}$ (from green to reddish color) in the freshly squeezed juice can be due to the presence of brown color resulting from degradation of melanoidins (Ibarz, Pagan, Panades, \& Garza, 2005). $\Delta E$ values were classified as slightly noticeable (between 0.5 and 1.5 ) according to Cserhalmi, Sass-Kiss, Toth-Markus, and Lechner (2006). Choi, Kim, and Lee (2002) suggested that a $\Delta E>2$ corresponds to visually perceptible differences in various products. Thus, the color of PCGJ and FSTGJ did not show visual difference compared to the untreated reference samples.

\subsection{Dose-response curves and results of biodosimetry}

UV dose-response curve of S. cerevisiae inoculated in PCGJ was shown in Fig. 3a. $136.08 \mathrm{~mJ} / \mathrm{cm}^{2}$ UV dose was resulted in $5.47 \mathrm{log} \mathrm{CFU} /$ $\mathrm{ml}$ reduction of $S$. cerevisiae in PCGJ within only $9 \mathrm{~min}$. This was due to high penetration ability of UV light in the clear juice. The doseresponse curve of spoilage flora of FSTGJ was depicted in Fig. 3b. Spoilage yeasts and LAB in FSTGJ exhibited a slight tailing at the high UV dose levels. Karel and Lund (2003) explained these phenomena by existence of suspended particles. It was found that the exposure of FSTGJ to UV light for $24 \mathrm{~min}$ at $282.24 \mathrm{~mJ} / \mathrm{cm}^{2}$ of UV dose decreased spoilage yeasts population by $3.00 \pm 0.16 \log \mathrm{CFU} / \mathrm{ml}$. Under the same conditions, $4.32 \pm 0.03 \log \mathrm{CFU} / \mathrm{ml}$ reduction was achieved for $\mathrm{LAB}$ (Fig. 3b). We obtained higher inactivation rates for spoilage microorganisms in grape juice samples than those reported by Noci et al. (2008). They treated freshly squeezed apple juice by UV-C irradiation using $1.63 \mathrm{~cm}$ juice depth and achieved $2.2 \mathrm{log} \mathrm{CFU} / \mathrm{ml}$ reduction in the total aerobic count under similar experimental conditions.

The Weibull model was used to determine the tailing based on both the scale parameter $(\alpha)$ and the shape parameter (or concavity index) $(\beta)$ (Table 4). For spoilage yeasts and $\mathrm{LAB}, \beta$ values were less than one showing that remaining cells have less probability of dying or they become increasingly more resistant during the longer exposure times (Van Boekel, 2002). On the other hand, for S. cerevisiae, $\beta$ was greater than 1 . A downward concavity might be related to weakening of the cells because of exposure to UV light and the speeding up of the destruction rate of those cells (Peleg \& Penchina, 2000). The scale parameter $\alpha$ is usually considered as a measure of the organism resistance (kinetic parameter) for treatment and shows the velocity of inactivation of the cells. $\alpha$ was found to be slightly higher for LAB than spoilage yeasts in FSTGJ. This was supported with $t_{\text {Rave }}$ values compared in Table 4. According to the data derived from the model, the inactivation of LAB was faster than spoilage yeasts. It was reported that yeasts were more resistant microorganisms to UV light than LAB due to their different DNA structures (Lopez-Malo \& Palau, 2005). On the other hand, spoilage yeasts in FSTGJ were more resistant to UV-C irradiation than S. cerevisiae in PCGJ. It is reported that inoculated microorganisms are more susceptible to UV light compared to natural microflora of the juice (El-Hag,

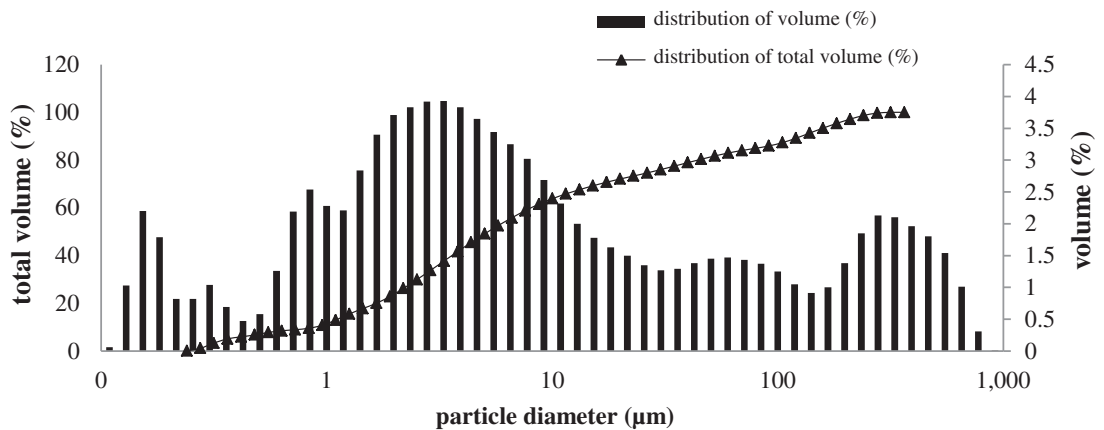

Fig. 2. Particle size distribution of freshly squeezed turbid white grape juice (FSTGJ). 
a

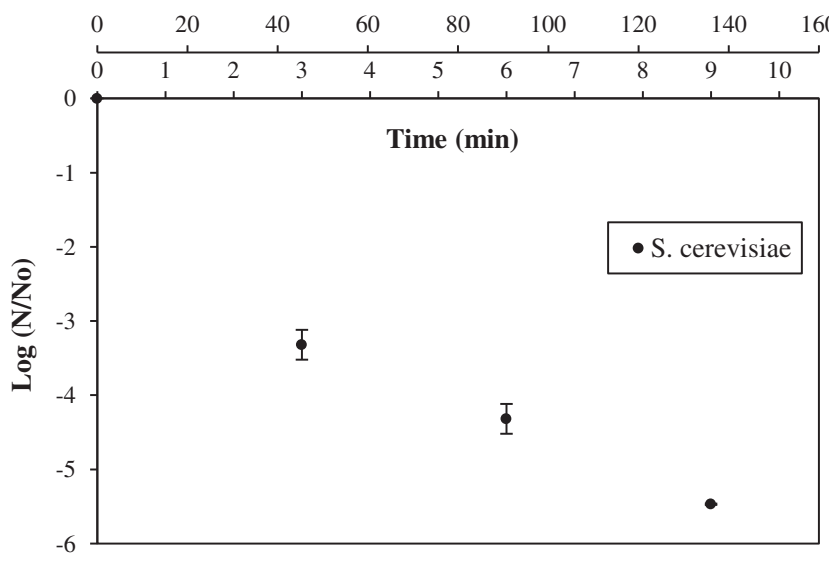

b

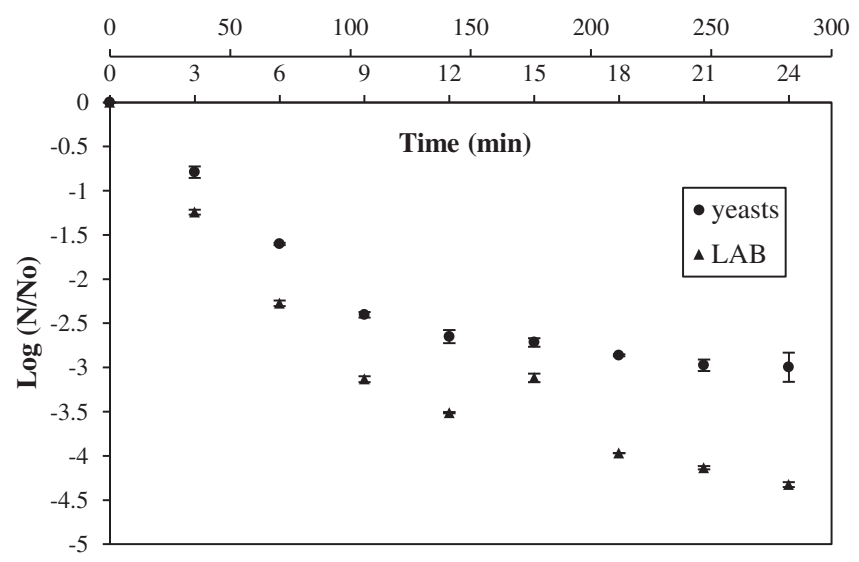

Fig. 3. UV dose-response curves: (a) pasteurized clear grape juice (PCGJ); (b) freshly squeezed turbid white grape juice (FSTGJ) (error bars are standard deviation of the mean of three experiments; where error bars are not displayed, they are smaller than the graph symbol).

Jayaram, \& Griffiths, 2006). It is still difficult to withdraw a definite conclusion about the resistivity of $S$. cerevisiae to UV-C irradiation. The clear shoulder and tailing part in the inactivation curves were not detected because a few numbers of data points were used and the larger standard deviation was observed in experimental data (Fig. 3a).

\subsection{Microbial inactivation efficiency of continuous flow UV system}

In this study a pilot scale continuous flow UV system was used and UV experiments were carried out in the laminar flow regime where Re numbers changed from 163.87 to 184.36 (Table 2). The effect of UV-C treatment on the inactivation of S. cerevisiae in PCGJ is shown in Fig. 4a. The population of $S$. cerevisiae was reduced by $3.39 \pm 0.04$ at a $24.27 \mathrm{~min}$ of exposure time and $65.50 \mathrm{~mJ} / \mathrm{cm}^{2}$ of UV dose. Guerrero-

Table 4

Weibull model parameters for spoilage yeasts, lactic acid bacteria (LAB) and Saccharomyces cerevisiae (NRRL Y-139) subjected to UV-C irradiation.

\begin{tabular}{lllll}
\hline Microorganism & $\alpha_{\text {ave }}(\min )$ & $\beta_{\text {ave }}$ & $t_{\text {Rave }}{ }^{*}(\min )$ & RMSE \\
\hline Spoilage yeasts & $1.02 \pm 0.02$ & $0.67 \pm 0.08$ & $3.21 \pm 1.31^{\mathrm{b}}$ & 0.0490 \\
LAB & $1.02 \pm 0.02$ & $0.77 \pm 0.08$ & $3.07 \pm 0.29^{\mathrm{b}}$ & 0.0408 \\
S. cerevisiae & $1.02 \pm 0.01$ & $1.43 \pm 0.36$ & $1.90 \pm 0.27^{\mathrm{C}}$ & 0.2957 \\
\hline
\end{tabular}

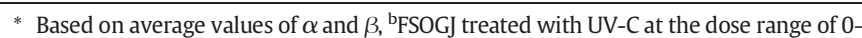
$282.24 \mathrm{~mJ} / \mathrm{cm} 2$, and ${ }^{\mathrm{C}} \mathrm{PCG}$ treated with UV-C at the dose range of $0-136.08 \mathrm{~mJ} / \mathrm{cm}^{2}$. a

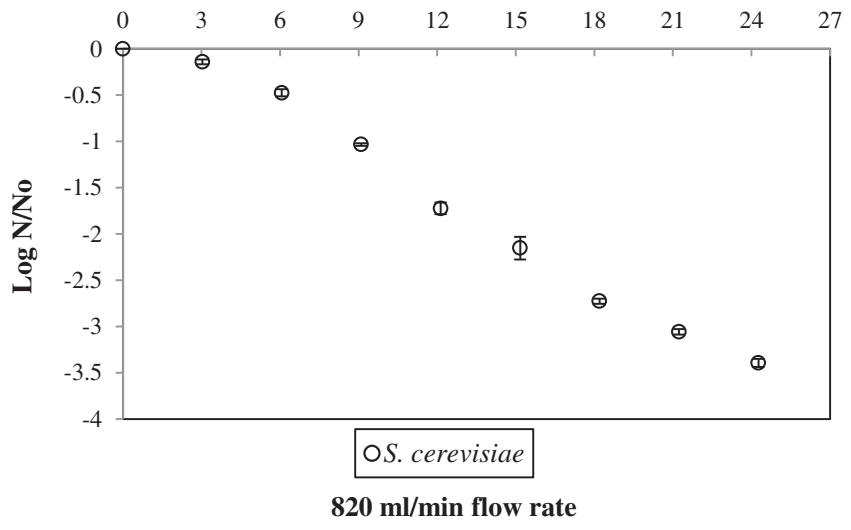

b

Time (sec)

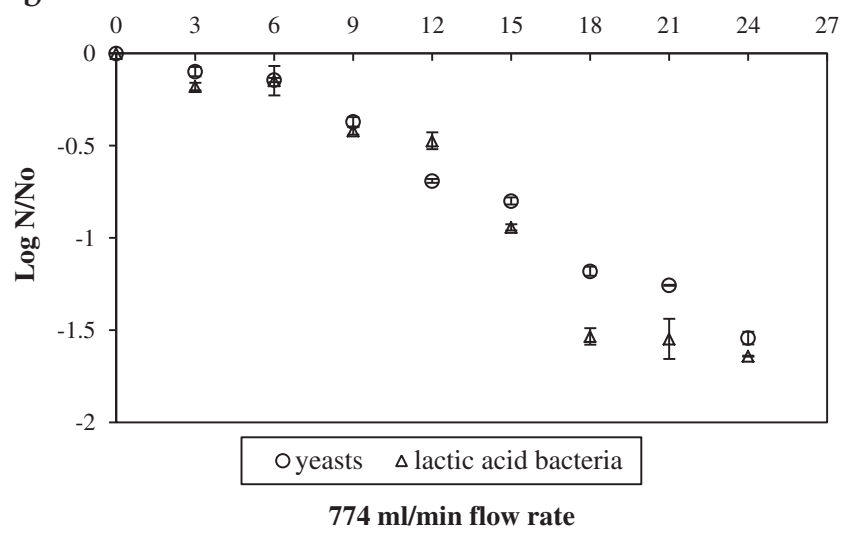

Fig. 4. Survival curves of S. cerevisiae in PCGJ (a), and spoilage microorganisms (yeast and lactic acid bacteria) in FSTGJ (b) treated with UV-C irradiation.

Beltran, Velti-Chanes, and Barbosa-Canovas (2009) used an annular continuous flow UV system to inactivate $S$. cerevisiae in red grape juice. They obtained only $0.53 \log$ microbial reductions after $30 \mathrm{~min}$ of UV treatment at a flow rate of $1.02 \mathrm{l} / \mathrm{min}$. It was stated that the violet color blocked the UV light from passing through the liquid and consequently, most of $S$. cerevisiae were not inactivated. The reason for lower inactivation obtained by Guerrero-Beltran et al. (2009) compared to those in this study ( $3.39 \log \mathrm{CFU} / \mathrm{ml}$ ) is probably due to the difference in the variety of grape juice used in the two studies. In summary, the clear grape juice was effectively treated with UV-C irradiation applied by a pilot scale UV reactor. Fig. 4b demonstrates the logarithmic reductions of natural spoilage microflora in FSTGJ. $1.54 \pm 0.04 \log$ and $1.64 \pm 0.03 \log \mathrm{CFU} / \mathrm{ml}$ reductions were obtained for spoilage yeasts and LAB in turbid grape juice after 24 min of UV light treatment at a flow rate of $774 \mathrm{ml} / \mathrm{min}$. Based on biodosimetry method, UV doses necessary to achieve these reductions for yeasts and LAB were estimated as $78.56 \mathrm{~mJ} / \mathrm{cm}^{2}$ and $67.97 \mathrm{~mJ} / \mathrm{cm}^{2}$, respectively. Johnson, Anil Kumar, Ponmurugan, and Gananamangai (2010) correlated the efficiency of UV inactivation with the types of microorganisms. Therefore, yeasts were more resistant to UV-C irradiation than lactic acid bacteria. Additionally, LAB reductions were higher than yeasts under studied conditions. Tran and Farid (2004) observed $3.07 \mathrm{log}$ and $2.09 \mathrm{log}$ reductions in aerobic plate and yeast counts in freshly squeezed orange juice at a UV dose of $123 \mathrm{~mJ} / \mathrm{cm}^{2}$. They achieved higher inactivation rate compared to our study because a thin-film continuous flow UV reactor was used in their study. The flow rate was $0.6 \mathrm{l} / \mathrm{min}$ and juice thickness was in the range of 0.21 and $0.48 \mathrm{~mm}$ that was much less than the UV penetration depth $(5.08 \mathrm{~cm})$ of the UV system used in this study. 


\section{Conclusions}

In the current study, the microbial inactivation efficiency of a pilot scale UV system for non-thermal treatment of clear and turbid grape juice was evaluated under conservative conditions. The clear grape juice was more effectively treated compared to FSTGJ using a pilot scale UV reactor described in this study. Although the system is mostly appropriate for the water disinfection, it was shown that the UV system (Wedeco-Durco AG Water Technology, Germany) has a potential application in the non-thermal treatment of clear juice products. Additionally, this work also showed the utilization of microbiological biodosimetry methodology for the UV dose prediction in a continuous UV system. The effect of UV-C irradiation on the physicochemical properties of grape juice samples before and after treatment was also evaluated. The soluble solids ( ${ }^{\circ} \mathrm{Brix}$ ) and $\mathrm{pH}$ of grape juice samples were not affected by UV-C treatment $(p>0.05)$. Although the color parameters i.e. $\mathrm{BI}, L^{*}, a^{*}$ and $b^{*}$ slightly were changed after UV-C irradiation, the color of PCGJ and FSTGJ did not show any visual difference compared to that of the untreated reference samples.

Although it was shown that the UV system, i.e. a typical of those used for water sterilization, can be utilized for UV-C treatment of clear juice products, there is still a need for research to investigate the effects of UV-C irradiation on the nutritional content, as well as the sensory qualities (taste, appearance, and flavor) of grape juice.

\section{Acknowledgment}

This study was supported by the Department of Food Engineering, Izmir Institute of Technology, Izmir, Turkey (2010IYTE09).

\section{References}

Betoret, E., Betoret, N., Carbonell, J. V., \& Fito, P. (2009). Effects of pressure homogenization on particle size and the functional properties of citrus juices. Journal of Food Engineering, 92, 18-23.

Bintsis, T., Litopoulou-Tzanetaki, E., \& Robinson, R. K. (2000). Existing and potential applications of ultraviolet light in the food industry-A critical review. Journal of the Science of Food and Agriculture, 80, 637-645.

Choi, M. H., Kim, G. H., \& Lee, H. S. (2002). Effects of ascorbic acid retention on juice colour and pigment stability in blood orange (Citrus sinensis) juice during refrigerated storage. Food Research International, 35, 753-759.

CiderSure. (2010). UV cider prurification system. Retrieved 9 April 2015, from http:// www.cidersure.com

Cserhalmi, Z., Sass-Kiss, A., Toth-Markus, M., \& Lechner, N. (2006). Study of pulsed electric field treated citrus juices. Innovative Food Science \& Emerging Technologies, 7(1), 49-54.

Donahue, D. W., Canitez, N., \& Bushway, A. A. (2004). UV inactivation of E. coli 0157:H7 in apple cider: Quality, sensory and shelf-life analysis. Journal of Food Processing \& Preservation, 28(5), 368-387.

El-Hag, A. H., Jayaram, S. H., \& Griffiths, M. W. (2006). Inactivation of naturally grown microorganisms in orange juice using pulsed electric fields. IEEE Transactions on Plasma Science, 34(4), 1412-1415.

Falguera, V., Pagan, J., \& Ibarz, A. (2011). Effect of UV irradiation on enzymatic activities and physicochemical properties of apple juices from different varieties. LWT- Food Science and Technology, 44(1), 115-119.

FAO (Food and Agriculture Organization of the United Nations) (1981s). Codex standard for grape juice preserved exclusively by physical means (world-wide standard). Codex Alimentarious Commission.

Forney, L. J., \& Pierson, J. R. (2003). Optimum photolysis in Taylor-Couette flow. AICHE Journal, 49(3), 727-733.

Gabriel, A. A., \& Nakano, H. (2009). Inactivation of Salmonella, E. coli and Listeria monocytogenes in phosphate-buffered saline and apple juice by ultraviolet and heat treatments. Food Control, 20, 443-446.

Garde-Cerdan, T., Arias-Gil, M., Marselles-Fontanet, A. R., Ancin-Azpilicueta, C., \& MartinBelloso, O. (2007). Effects of thermal and non-thermal processing treatments on fatty acids and free amino acids of grape juice. Food Control, 18, 473-479.

Gayan, E., Monfort, S., Alvarez, I., \& Condon, S. (2011). UV-C inactivation of Escherichia coli at different temperatures. Innovative Food Science E' Emerging Technologies, 12(4), 531-541.
Gomez, P. L., Alzamora, S. M., Castro, M. A., \& Salvatori, D. M. (2010). Effect of ultraviolet-C light dose on quality of cut-apple: Microorganism, color and compression behavior. Journal of Food Engineering, 98, 60-70.

Guerrero-Beltran, J. A., \& Barbosa-Canovas, G. V. (2004). Advantages and limitations on processing foods by UV light. Food Science and Technology International, 10, 137-147.

Guerrero-Beltran, J. A., Velti-Chanes, J., \& Barbosa-Canovas, G. V. (2009). Ultraviolet-C light processing of grape, cranberry and grapefruit juices to inactivate Saccharomyces cerevisiae. Journal of Food Process Engineering, 32, 916-932.

Hakguder, B. (2009). UV disinfection of some of the fruit juices. ((Master's thesis). Retrieved from) http://openaccess.iyte.edu.tr

Ibarz, A., Pagan, J., Panades, R., \& Garza, S. (2005). Photochemical destruction of color compounds in fruit juices. Journal of Food Engineering, 69, 155-160.

Johnson, K. M., Anil Kumar, M. R., Ponmurugan, P., \& Gananamangai, M. B. (2010) Ultraviolet radiation and its germicidal effect in drinking water purification. Journal of Phytology, 2(5), 12-19.

Karel, M., \& Lund, D. B. (2003). Physical principles of food preservation. New York: Marcel Dekker.

Kaya, Z. (2011). Disinfection of white grape juice by using continuous flow UV reactor. (Master's Thesis). Retrieved from http://openaccess.iyte.edu.tr

Koutchma, T. (2008). UV light for processing foods. Ozone: Science E Engineering, 30(1), 93-98.

Koutchma, T., \& Parisi, B. (2004). Biodosimetry of Escherichia coli UV inactivation in model juices with regard to dose distribution in annular UV reactors. Journal of Food Science, 69(1), 14-22.

Koutchma, T., Parisi, B., \& Unluturk, S. K. (2006). Evaluation of UV dose in flow-through reactors for fresh apple juice and cider. Chemical Engineering Communications, 193, 715-728.

Koutchma, T. N., Forney, L. J., \& Moraru, C. I. (2009). Ultraviolet light in food technology: Principles and applications. New York: CRC Press.

Lopez-Malo, A., \& Palau, E. (2005). Ultraviolet light and food preservation. In G. V. Barbosa-Canovas, M. S. Tapia, \& M. P. Cano (Eds.), Novel food processing technologies (pp. 405-422). Madrid: CRC Press.

Müller, A., Briviba, K., Graf, V., Greiner, R., Herrmann, C., Kuballa, T., \& Stahl, M. R. (2013) UV-C treatment using a dean vortex technology-Impact on apple juice enzymes and toxicological potential. Innovative Food Science E Emerging Technologies, 20, 238-243.

Ngadi, M. Smith, J. P. \& Cayouette, B. (2003). Kinetics of ultraviolet light inactivation of Escherichia coli 0157:H7 in liquid foods. Journal of the Science of Food and Agriculture, 83, 1551-1555.

Noci, F., Riener, J., Walkling-Ribeiro, M., Cronin, D. A., Morgan, D. J., \& Lyng, J. G. (2008). Ultraviolet irradiation and pulsed electric fields (PEF) in a hurdle strategy for the preservation of fresh apple juice. Journal of Food Engineering, 85, 141-146.

Ochoa-Velasco, C. E., \& Guerrero-Beltran, J. A. (2013). Short-wave ultraviolet-C light effect on pitaya (Stenocereus griseus) juice inoculated with Zygosaccharomyces bailii. Journa of Food Engineering, 117, 34-41.

Palou, E., Lopez-Malo, A., Barbosa-Canovas, G. V., Welti-Chanes, J., \& Swanson, B. G. (1999). Polyphenoloxidase activity and color of blanched and high hydrostatic pressure treated banana puree. Journal of Food Science, 64(1), 42-45.

Peleg, M., \& Penchina, C. M. (2000). Modeling microbial survival during exposure to a lethal agent with varying intensity. Critical Reviews in Food Science and Nutrition, 40(2) 159-172.

Rameshkumar, A., Sivasudha, T., Jeyadevi, R., Arul Ananth, D., \& Pradeepha, G. (2012). Effect of environmental factors [air and UV-C irradiation] on some fresh fruit juices European Food Research and Technology, 234, 1063-1070.

Telis-Romero, J., Thomas, C. E. P., Bernardi, M., Telis, V. R. N., \& Gabas, A. L. (2006) Rheological properties and fluid dynamics of egg yolk. Journal of Food Engineering, 74, 191-197.

Torkamani, A. E., \& Niakousari, M. (2011). Impact of UV-C light on orange juice quality and shelf life. International Food Research Journal, 18(4), 1265-1268.

Tournas, V. H., Heeres, J., \& Burgess, L. (2006). Moulds and yeasts in fruit salads and fruit juices. Food Microbiology, 23(7), 684-688.

Tran, M. T. T., \& Farid, M. (2004). Ultraviolet treatment of orange juice. Innovative Food Science \&' Emerging Technologies, 5, 495-502.

Unluturk, S., Atilgan, M. R., Baysal, A. H., \& Tarı, C. (2008). Use of UV-C radiation as a nonthermal process for liquid egg products (LEP). Journal of Food Engineering, 85, 561-568.

Unluturk, S., Atilgan, M. R., Baysal, A. H., \& Unluturk, M. S. (2010). Modelling inactivation kinetics of liquid egg white exposed to UV-C irradiation. International Journal of Food Microbiology, 142, 341-347.

Unluturk, S. K., Arastoopour, H., \& Koutchma, T. (2004). Modeling of UV dose distribution in a thin-film UV reactor for processing of apple cider. Journal of Food Engineering, 65(1), 125-136.

Van Boekel, M. A. J. S. (2002). On the use of the Weibull model to describe thermal inactivation of microbial vegetative cells. International Journal of Food Microbiology, 74, 139-159.

Wedeco [Operating Manual] (2007). Wedeco UV-verfahrenstechnik GmbH, Germany.

Wright, J. R., Sumner, S. S., Hackney, C. R., Pierson, M. D., \& Zoecklein, B. W. (2000). Efficacy of ultraviolet light for reducing Escherichia coli 0157:H7 in unpasteurized apple cider. Journal of Food Protection, 63(5), 563-567. 